\title{
Numerical investigation of particle deposition inside aero-shielded solar cyclone reactor: A promising solution for reactor clogging
}

\author{
D. Jaya Krishna ${ }^{1}$, Nesrin Ozalp* \\ Texas AE'M University at Qatar, Mechanical Engineering Department, P.O. Box 23874, Doha, Qatar
}

\section{A R T I C L E I N F O}

\section{Article history:}

Received 4 August 2012

Received in revised form 17 December 2012

Accepted 19 December 2012

Available online 4 February 2013

\section{Keywords:}

Solar reactor

Carbon deposition

Reactor clogging

Cyclone flow

Two-phase

\begin{abstract}
A B S T R A C T
Solar cracking of methane is considered to be an attractive option due to its $\mathrm{CO}_{2}$ free hydrogen production process. Carbon particle deposition on the reactor window, walls and exit is a major obstacle to achieve continuous operation of methane cracking solar reactors. As a solution to this problem a novel "aeroshielded solar cyclone reactor" was created. In this present study the prediction of particle deposition at various locations for the aero-shielded reactor is numerically investigated by a Lagrangian particle dispersion model. A detailed three dimensional computational fluid dynamic (CFD) analysis for carbon deposition at the reactor window, walls and exit is presented using a Discrete Phase Model (DPM). The flow field is based on a RNG $\mathrm{k}-\varepsilon$ model and species transport with methane as the main flow and argon/ hydrogen as window and wall screening fluid. Flow behavior and particle deposition have been observed with the variation of main flow rates from $10-20 \mathrm{~L} / \mathrm{min}$ and with carbon particle mass flow rate of $7 \times 10^{-6}$ and $1.75 \times 10^{-5} \mathrm{~kg} / \mathrm{s}$. In this study the window and wall screening flow rates have been considered to be $1 \mathrm{~L} / \mathrm{min}$ and $10 \mathrm{~L} / \mathrm{min}$ by employing either argon or hydrogen. Also, to study the effect of particle size simulations have also been carried out (i) with a variation of particle diameter with a size distribution of $0.5-234 \mu \mathrm{m}$ and (ii) by taking $40 \mu \mathrm{m}$ mono sized particles which is the mean value for the considered size distribution. Results show that by appropriately selecting the above parameters, the concept of the aero-shielded reactor can be an attractive option to resolve the problem of carbon deposition at the window, walls and exit of the reactor.
\end{abstract}

(c) 2013 Elsevier Inc. All rights reserved.

\section{Introduction}

Solar thermal cracking of natural gas is an encouraging option for the production of hydrogen and carbon black as stated by Flamant et al. (2011), Patrianakos et al. (2012). Due to the absence of $\mathrm{CO}_{2}$ production in the process, it is viable option for sustainable energy. In spite of this attractive feature the technology is yet to be commercialized due to challenges like protecting the window from carbon particles, reactor exit clogging due to carbon particle deposition, protection of the reactor against thermal shocks and loss of solar power from the window due to multiple reflections. Therefore, researchers have focused their attention on the understanding of various performance parameters like reaction kinetics, species and heat transfer, flow behavior and particle deposition. Steinfeld and his research group Hirsch et al. (2001), Hirsch and Steinfeld (2004), Trommer et al. (2004) and Maag et al. (2009) have extensively carried out experimental and thermodynamic analysis for the thermal decomposition of methane in a vortex flow solar reac-

\footnotetext{
* Corresponding author. Tel.: +974 6686 2832; fax: +974 44230066 .

E-mail address: nesrin.ozalp@qatar.tamu.edu (N. Ozalp).

1 Present address: Mechanical Engineering Department, BITS Pilani, Hyderabad Campus, Hyderabad 500 078, India.
}

tor. An analytical model was formulated by coupling heat transfer and chemical kinetics for a two phase solid gas reacting flow. It was mentioned that the direct solar irradiation of particle suspensions with vortex flow provided an efficient mechanism of heat transfer, however carbon particle feeding was active during the experiment due to the problem of "sedimentation and excessive deposition of dust on the window" (Hirsch and Steinfeld, 2004). Trommer et al. (2004) and Maag et al. (2009) reported that with the introduction of carbon particles there is a considerable enhancement of reaction rate due to the larger specific surface reaction and efficient radiation heat transfer for the reaction site. Higher methane conversions were achieved by varying operational parameters like inlet solar power, particle volume fraction, total gas volume flow and inlet methane mole fraction.

Based on direct heating concept, Abanades and Flamant (2005, $2006,2007,2008$ ) studied the effect of graphite nozzle geometry for a $1 \mathrm{~kW}$ solar reactor. Methane conversion and hydrogen yield were studied by varying the methane flow rate and reaction temperature. Argon as a carrier gas was injected at the top of the Pyrex glass window to prevent the carbon particle deposition. In Abanades and Flamant (2005), it was mentioned that they faced the difficulty of preventing carbon deposition in the reaction zone and also on the window. They also mentioned that the formed 


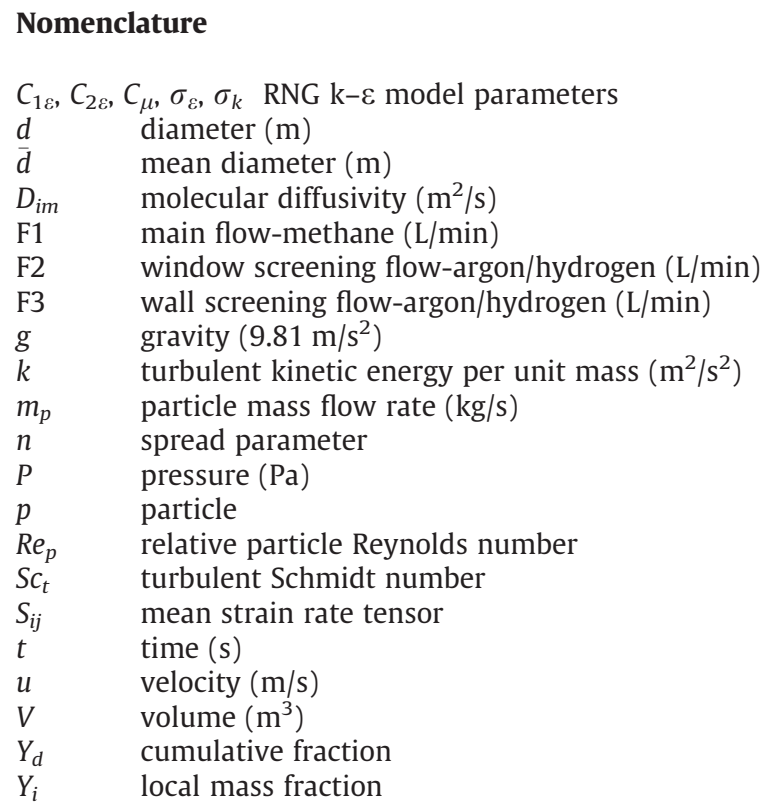

carbon particulates further decompose causing rapid reactor clogging and temperature decrease. As a follow up study, the same research group designed a $10 \mathrm{~kW}$ tubular solar reactor based on an indirect heating concept to overcome the problem of particle deposition at the window as seen in Rodat et al. (2009a,b), and Rodat et al. (2010).

To protect the inner tube wall of the reactor from carbon particle deposition Dahl et al. (2004) fed argon into the annular region between the two graphite tubes and forced the gas through the porous tube wall. Their objective was to create an aerodynamic blanket on the inner wall of the reactor tube for carbon particle deposition. Based on their experimental observations, Dahl et al. (2005) mentioned that for long periods of time the deposition of carbon black was apparent on the porous tube wall in the hot zone of the reactor. They also highlighted that it is important to understand the cause for the deposition of carbon particles and its effect of system parameters. CFD analysis was also carried considering the steady state for a two dimensional axi-symmetric geometry. Their parametric study includes variations of tube permeability, gas flow rate, gas inlet temperature and gas composition. It was observed that the flow rates of the inlet gas streams do not dramatically affect the performance of the porous tube wall. Higher temperatures were observed at the center of the core when hydrogen is used as a sweeping gas instead of Argon.

Kogan and Kogan (2002) came with another effective way of screening the window for particle deposition by providing a curtain of auxiliary gas stream near the window. They carried out flow visualization tests for different reactor models and investigated solar thermal methane splitting with unseeded reactor Kogan and Kogan (2003). Later, Kogan et al. (2004) experimentally observed the particle deposition on reactor window at room temperature for different reactor configurations by varying flow conditions.

To gain access to the flow field in the region where it is experimentally inaccessible, CFD has become a powerful tool to analyze and understand the flow physics. There are several major computational studies done by the above research groups to analyze the flow field, temperature and concentration distribution etc. inside the solar reactors. One of the earliest study was hydrogen production via a solar thermal process by Meier et al. (1996) for a two step water splitting process. To study the effect of the radial air jet and air stream into the reactor through the aperture they simulated the particle trajectory. Heat transfer analysis was carried out by neglecting radiation. Another CFD work was done by Steinfeld et al. (1998) for $\mathrm{ZnO}$ reduction and methane reforming. It was shown that vortex flow reactor is an efficient reactor concept for enhanced heat transfer. The helical grooves led to the formation of helical path for the fluid and particles flow which in turn provided longer residence time for the particles inside the reactor chamber. Abanades and Flamant (2006) used Femlab 3.1 software to predict the temperature profile, chemical conversion and molar concentration of methane for their nozzle type laboratory scale solar reactor. In their CFD model mass and energy transport with chemical reaction kinetics were coupled. The kinetic constants for first order reaction kinetics were adopted from Trommer et al. (2004). The simulation results showed that the reacting gas was heated more homogeneously when the temperature gradients were smaller. In another study, Abanades and Flamant (2008) carried out computational flow model based on the finite volume method by incorporating fluid flow, heat and mass transfer, and chemical reaction using Fluent 6.2. The two dimensional axi-symmetric two phase CFD model was considered to determine the hydrogen concentration and velocity at reactor outlet, velocity and temperature profiles inside the reactor, and methane conversion. Later, Rodat et al. (2009a) carried out a 3-D CFD simulation of non symmetrical reactor geometry to predict the temperature distribution in the reactor. It was observed that the gas temperature was equal to the wall temperature in the irradiated part of the tubes and hotter than the walls in the insulated section leading to thermophoretic carbon deposition on reactor wall. In one of their recent studies, they did thermal simulations of a $53 \mathrm{~kW}$ solar reactor using Fluent 12.0.16 (Rodat et al., 2010). It was observed that $66 \%$ of the incoming power was lost due to high temperature gradient through the water cooled aluminum front face. To overcome this issue an optimized design on front face was proposed and simulated which improved the absorption efficiency.

Wyss et al. (2007) considered multiple concentric tube reactor of Dahl et al. $(2004,2005)$. By conducting experiments they could attain 94\% (approx.) conversion at a temperature of $2173 \mathrm{~K}$ and at a 
flow rate of $1.67 \times 10^{-5} \mathrm{~m}^{3} / \mathrm{s}$. They developed a one dimensional non-isothermal kinetic model which could satisfactorily predict the experimental data. Simulations were carried out for the process using HYSYS software. The study also discusses the environmental, reactor design and economic aspects of solar thermal decarbonization of methane.

Kogan et al. (2007) carried out CFD simulations for a solar reactor by considering isothermal conditions for different temperatures without incorporating cracking of methane. By referring to stream function profiles for a 2D axi-symmetric geometry the flow physics for particle deposition was explained. Klein et al. (2007) simulated the fluid dynamics and heat transfer of carbon particles in a directly irradiated solar receiver without including chemical kinetics. Their simulation results showed good agreement with the measured wall temperature distribution whereas considerable variation was observed in the exit gas temperature.

Ozalp and Kanjirakat (2010a) numerically investigated the influence of inlet angles, main flow rate, screening flow rate, screening gases on particle deposition at reactor window, walls and exit. By employing a Discrete Phase Model with particle tracking they could successfully predict the particle deposition on reactor window as experimentally observed by Kogan et al. (2004). Later the effect of carbon particle seeding for the improvement of solar reactor performance was studied by Ozalp and Kanjirakat (2010b). It was observed that the carbon particle seeding inside the reactor considerably increased the temperature inside the reactor. Another study by Ozalp and JayaKrishna (2010) was a numerical study and comparison with the experimental results for vortex flow reactor of Hirsch and Steinfeld (2004). Results were presented in terms of outlet temperatures, contours for static temperature and concentration of chemical species.

Recently, Patrianakos et al. (2011) developed a one-dimensional reactor-particle population model and applied to a $10 \mathrm{~kW}$ indirectly heated unseeded reactor. The simulated results are compared with experimental methane conversion for the PROMESCNRS solar reactor experiments. Valdes-Parada et al. (2011) numerically simulated the phenomena of heat and mass transport for an indirectly heated cubic cavity solar reactor. The solar radiation enters the cavity through a quartz window and a graphite reaction tube which is fed with argon-methane mixture is made to settle vertically inside the cavity. When the reaction chamber attains a temperature of $2000 \mathrm{~K}$ they could observe the methane conversion of $100 \%$. Results were presented in terms of velocity, temperature and concentration profiles.

It may be observed from the above literature that several research groups have introduced different reactor geometries to predict the solar reactor's carbon particle deposition at the reactor window and exit. However the problem still persists when the solar reactor is operated for long hours. In search of a solution for the above problem researchers are still in the process of coming up with different reactor concepts and models for the commercialization of solar methane cracking process. In pursuit of a possible solution for the reactor's window and exit carbon particle deposition the concept of an "aero-shielded solar cyclone reactor" is proposed. The study aims at the thorough numerical investigation of this concept to predict the particle deposition for different flow conditions at the window and exit locations of the reactor.

\section{CFD methodology}

In the present study the reactor is provided with the main flow of methane (F1), window screening (F2) and wall screening (F3) of argon/hydrogen as shown in Fig. 1. According to the reactor conditions, the flow is considered to be isothermal with species transfer. Methane is injected through 18 impeller disk jets with each of
$2 \mathrm{~mm}$ diameter from the top center of the reactor with a $45^{\circ}$ angle at different flow rates as provided in Table 1 . The objective is to create a vortex flow for methane in the center without interfering to the walls in order to prevent carbon black deposition. The purpose of the vortex flow inside the reactor is to increase the residence time of methane to achieve higher methane conversion. The three-dimensional geometry for simulations is built and a non-uniform unstructured grid is generated using GAMBIT. The details of the problem geometry are provided in Fig. 1. The basic geometry with adapted grid used for simulations is shown in Fig. 2.

It may be noted that the reaction is not considered in the simulations since the present study is to observe the flow field and the mixing behavior. Since methane decomposition is significant at elevated temperatures of above $700{ }^{\circ} \mathrm{C}$, the transport properties (i.e. density and viscosity) are taken at $1000^{\circ} \mathrm{C}$ for simulations of the present study. A commercial finite volume based tool, Ansys 13.0 is employed in the simulations. These simulations involve fluid flow, turbulent species transport and particle tracking. To evaluate the turbulent quantities, RNG $\mathrm{k}-\varepsilon$ turbulence model has been employed. As the present study is based on low Reynolds number and swirling flows the RNG $\mathrm{k}-\varepsilon$ turbulence model has been selected. The criteria for the selection of RNG $k-\varepsilon$ has been discussed in detail and may be referred to Ozalp and JayaKrishna (2010). The turbulence model parameters and variables employed in Eq. (6) can be referred from Fluent (2006), Habibi et al. (2007) and Vidyasagar et al. (2011). The flow is considered to be incompressible and by Stokes hypothesis the bulk viscosity is zero. The steady state equations pertaining to the present study are as follows

Continuity equation:

$\frac{\partial\left(\rho u_{i}\right)}{\partial x_{i}}=0$

Momentum equation:

$\frac{\partial\left(\rho u_{i} u_{j}\right)}{\partial x_{j}}=\frac{\partial P_{e f f}}{\partial x_{i}}+\frac{\partial}{\partial x_{j}}\left[\mu_{e f f}\left(\frac{\partial u_{i}}{\partial x_{j}}+\frac{\partial u_{j}}{\partial x_{i}}\right)\right]-\rho g_{i}$

$\mathrm{k}$ - equation:

$\frac{\partial\left(\rho k u_{i}\right)}{\partial x_{i}}=\frac{\partial}{\partial x_{j}}\left(\left(\mu+\frac{\mu_{t}}{\sigma_{k}}\right) \frac{\partial k}{\partial x_{j}}\right)+G_{k}-\rho \varepsilon$

$\varepsilon$ - equation:

$\frac{\partial\left(\rho \varepsilon u_{i}\right)}{\partial x_{i}}=\frac{\partial}{\partial x_{j}}\left(\left(\mu+\frac{\mu_{t}}{\sigma_{\varepsilon}}\right) \frac{\partial \varepsilon}{\partial x_{j}}\right)+C_{1 \varepsilon} \frac{\varepsilon}{k} G_{k}-C_{2 \varepsilon} \rho \frac{\varepsilon^{2}}{k}-R_{\varepsilon}$

Species transport equation:

$\frac{\partial\left(\rho u_{j} Y_{i}\right)}{\partial x_{j}}=\frac{\partial}{\partial x_{j}}\left[\left(\rho D_{i m}+\frac{\mu_{t}}{S c_{t}}\right) \frac{\partial Y_{i}}{\partial x_{j}}\right] \quad i=1,2 \ldots, N-1$

where

$\mu_{\text {eff }}=\mu+\mu_{t}$

$\mu_{t}=\rho C_{\mu} \frac{k^{2}}{\varepsilon}$

$P_{\text {eff }}=P+\frac{2}{3} \rho k$

$C_{\mu}=0.0845$

$C_{1 \varepsilon}=1.42$

$C_{2 \varepsilon}=1.68$ 


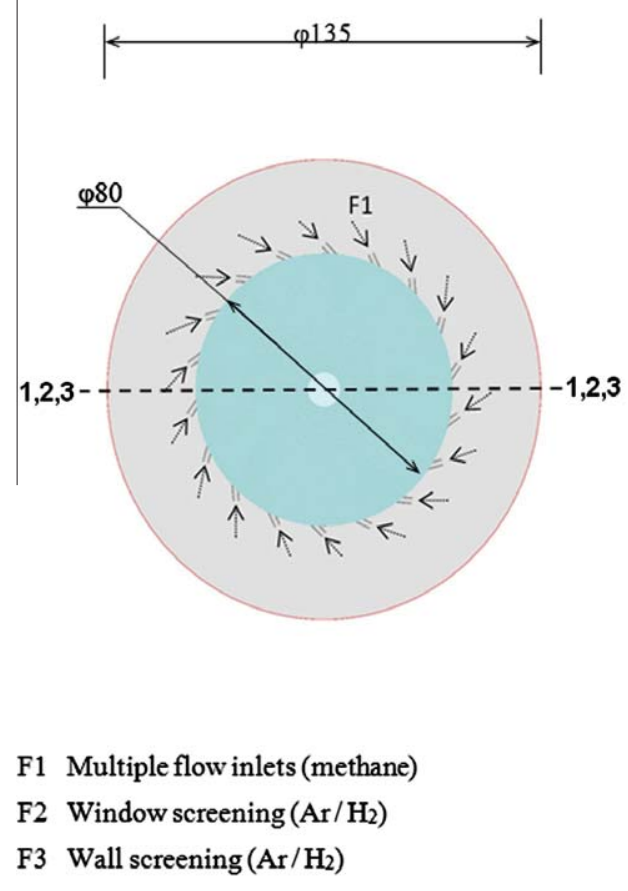

(a)

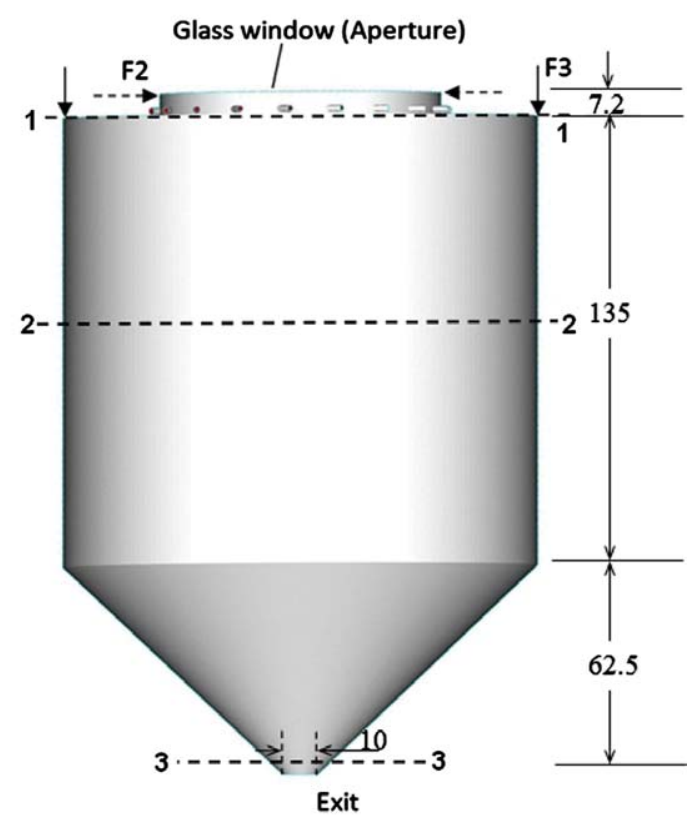

All dimensions in

Fig. 1. Aero-shielded solar cyclone reactor: (a) top view (b) front view.

$C_{3 \varepsilon}=\tanh \mid \frac{u_{3}}{\sqrt{u_{1}^{2}+u_{2}^{2}}}$

$G_{k}=\mu_{t} S_{i j} \frac{\partial u_{i}}{\partial x_{j}}$

$R_{\varepsilon}=\frac{C_{\mu} \rho \eta^{3}\left(1-\eta / \eta_{0}\right)}{1+\beta \eta^{3}} \frac{\varepsilon^{2}}{k}$

$\eta=\frac{S k}{\varepsilon}, \quad S=\left(2 S_{i j} S_{i j}\right)^{1 / 2}, \quad \eta_{o}=4.38, \beta=0.012$

$S_{i j}=\frac{\left(\frac{\partial u_{i}}{\partial x_{j}}+\frac{\partial u_{j}}{\partial x_{i}}\right)}{2}$

$\sigma_{k}=0.7179, \quad \sigma_{\varepsilon}=0.7179$

$\rho=\frac{1}{\sum \frac{Y_{i}}{\rho_{i}}}$

$\mu=\sum Y_{i} \mu_{i}$

\subsection{Particle tracking}

A DPM (Discrete Phase Model) is used to evaluate the particle trajectory through the continuous phase of gas. The motion of the particulate phase is done by integrating the force balance on the particle in the Lagrangian reference frame. The particle trajectory is thus calculated as follows

$\frac{d u_{p, i}}{d t}=F_{D}\left(u_{i}-u_{p, i}\right)+\frac{g_{i}\left(\rho_{p}-\rho\right)}{\rho_{p}}$ where $F_{D}=\left(\frac{18 \mu}{\rho_{p} d_{p}^{2}}\right) \frac{C_{D} \mathrm{Re}_{p, i}}{24}$ and the Reynolds number is:

$\operatorname{Re}_{p, i}=\frac{\rho_{p} d_{p}\left|u_{p, i}-u\right|}{\mu}$

The governing equations are solved using the finite volume method. SIMPLE algorithm has been employed for pressure velocity coupling. The convective terms of the momentum, species, turbulent kinetic energy and turbulent dissipation rate equations are discretized using the second order upwinding scheme.

The DPM concentration provides a measure of total concentration of discrete phase (particle) in a continuous cell and can be given by the resident time and mass flow by Eq. (9).

$\rho_{D P M}=\int_{t} \frac{\dot{m}_{p}}{V_{\text {cell }}} d t$

The DPM concentration thus provides an estimate of the density of the solid in a particular region. It shows areas where the particle loading is high and where the maximum probability of deposition can occur.

\subsection{Particle size distribution}

In the present study the carbon particles are fed along the main flow (F1) as shown in Fig. 1. The details of particle injection in simulations have been taken for activated charcoal (Fluka, 05120). Particle size analysis of the activated charcoal sample is carried out by laser diffraction particle size analyzer in a tornado dry powder system module (LS 13 320, laser diffraction particle size analyzer, Beckmann Coulter). A cumulative volume fraction of the sample considered is shown in Fig. 3. The mean particle diameter $(\bar{d})$ obtained experimentally from particle size analyzer is about $40 \mu \mathrm{m}$. In the present simulations the details for particle size distribution is defined by fitting the size distribution data to the Rosin-Rammler equation. 
Table 1

Details of the parametric study.

\begin{tabular}{|c|c|c|c|c|c|c|c|c|c|c|c|}
\hline \multirow[t]{2}{*}{ Case } & \multirow{2}{*}{$\begin{array}{l}\text { Main flow } \\
\text { (F1) (L/ } \\
\text { min) }\end{array}$} & \multirow{2}{*}{$\begin{array}{l}\text { Window } \\
\text { screening (F2) } \\
\text { (L/min) }\end{array}$} & \multirow{2}{*}{$\begin{array}{l}\text { Wall } \\
\text { screening } \\
(\mathrm{F} 3)(\mathrm{L} / \mathrm{min})\end{array}$} & \multicolumn{3}{|c|}{ Type of gas/fluid } & \multirow{2}{*}{$\begin{array}{l}\text { Mass flow rate } \\
\text { of particle } \\
(\mathrm{kg} / \mathrm{s})\end{array}$} & \multirow{2}{*}{$\begin{array}{l}\text { Diameter } \\
\text { details }(\mu \mathrm{m})\end{array}$} & \multirow{2}{*}{$\begin{array}{l}\text { Volume } \\
\text { fraction } \\
(\mathrm{Fv})\end{array}$} & \multirow{2}{*}{$\begin{array}{l}\text { Window } \\
\text { deposition }\end{array}$} & \multirow{2}{*}{$\begin{array}{l}\text { Exit } \\
\text { Deposition } \\
\left(\mathrm{kg} / \mathrm{m}^{3}\right)\end{array}$} \\
\hline & & & & $\mathrm{F} 1$ & $\mathrm{~F} 2$ & F3 & & & & & \\
\hline 1 & 10 & 1 & 10 & Methane & Argon & Argon & $7.00 \mathrm{E}-06$ & Nonuniform & $1.0 \mathrm{E}-05$ & 0 & 0.058 \\
\hline 2 & 10 & 1 & 10 & Methane & Argon & Argon & $1.75 \mathrm{E}-05$ & Nonuniform & $2.5 \mathrm{E}-05$ & 0 & 0.132 \\
\hline 3 & 10 & 1 & 10 & Methane & Argon & Argon & $7.00 \mathrm{E}-06$ & 40 & $1.0 \mathrm{E}-05$ & 0 & $3.11 \mathrm{E}-05$ \\
\hline 4 & 10 & 1 & 10 & Methane & Argon & Argon & $1.75 \mathrm{E}-05$ & 40 & $2.5 \mathrm{E}-05$ & 0 & 0.075 \\
\hline 5 & 15 & 1 & 10 & Methane & Argon & Argon & $7.00 \mathrm{E}-06$ & Nonuniform & $8.1 \mathrm{E}-06$ & 0.000216 & 0.0935 \\
\hline 6 & 15 & 1 & 10 & Methane & Argon & Argon & $1.75 \mathrm{E}-05$ & Nonuniform & $2.0 \mathrm{E}-05$ & 0.0342 & 0.204 \\
\hline 7 & 15 & 1 & 10 & Methane & Argon & Argon & $7.00 \mathrm{E}-06$ & 40 & $8.1 \mathrm{E}-06$ & 0 & 0.00055 \\
\hline 8 & 15 & 1 & 10 & Methane & Argon & Argon & $1.75 \mathrm{E}-05$ & 40 & $2.0 \mathrm{E}-05$ & 0 & 0.288 \\
\hline 9 & 20 & 1 & 10 & Methane & Argon & Argon & $7.00 \mathrm{E}-06$ & Nonuniform & $6.8 \mathrm{E}-06$ & 0.0045 & 0.149 \\
\hline 10 & 20 & 1 & 10 & Methane & Argon & Argon & $1.75 \mathrm{E}-05$ & Nonuniform & $1.7 \mathrm{E}-05$ & 0.0097 & 0.348 \\
\hline 11 & 20 & 1 & 10 & Methane & Argon & Argon & $7.00 \mathrm{E}-06$ & 40 & $6.8 \mathrm{E}-06$ & 0 & 0.0192 \\
\hline 12 & 20 & 1 & 10 & Methane & Argon & Argon & $1.75 \mathrm{E}-05$ & 40 & $1.7 \mathrm{E}-05$ & 0 & 0.577 \\
\hline 13 & 10 & 1 & 10 & Methane & Hydrogen & Argon & $7.00 \mathrm{E}-06$ & Nonuniform & $1.0 \mathrm{E}-05$ & 0.006 & 0.007 \\
\hline 14 & 15 & 1 & 10 & Methane & Hydrogen & Argon & $7.00 \mathrm{E}-06$ & Nonuniform & $8.1 \mathrm{E}-06$ & 0.005 & 0.106 \\
\hline 15 & 20 & 1 & 10 & Methane & Hydrogen & Argon & $7.00 \mathrm{E}-06$ & Nonuniform & $6.8 \mathrm{E}-06$ & 0.0022 & 0.1203 \\
\hline 16 & 10 & 1 & 10 & Methane & Hydrogen & Hydrogen & $7.00 \mathrm{E}-06$ & Nonuniform & $1.0 \mathrm{E}-05$ & 0.0065 & 0.318 \\
\hline 17 & 15 & 1 & 10 & Methane & Hydrogen & Hydrogen & $7.00 \mathrm{E}-06$ & Nonuniform & $8.1 \mathrm{E}-06$ & 0.0052 & 0.454 \\
\hline 18 & 20 & 1 & 10 & Methane & Hydrogen & Hydrogen & $7.00 \mathrm{E}-06$ & Nonuniform & $6.8 \mathrm{E}-06$ & 0.0021 & 0.51 \\
\hline
\end{tabular}

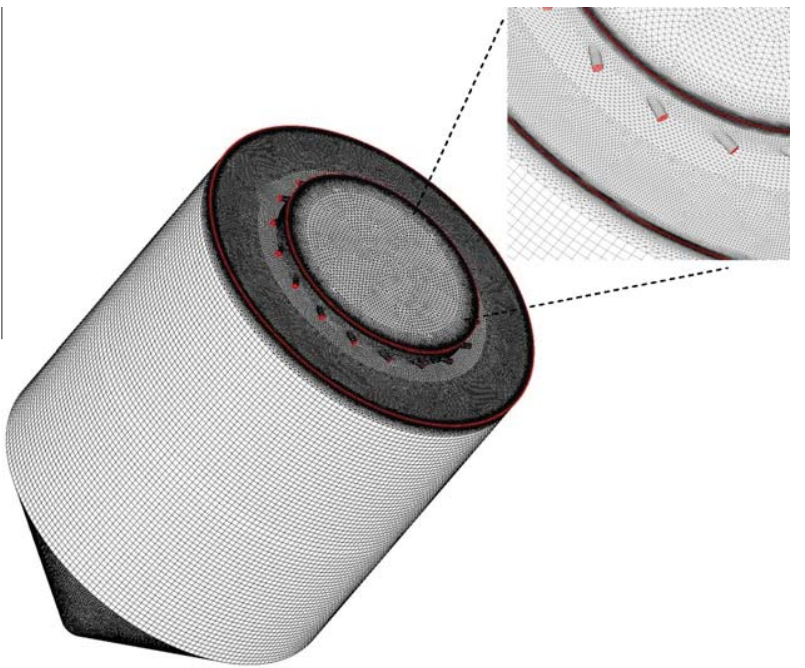

Fig. 2. Meshed geometry of aero-shielded solar cyclone reactor.

$Y_{d}=e^{-(d / \bar{d})^{n}}$

where $Y_{d}$ refers to the cumulative fraction with diameter greater than $d$ and, $\bar{d}$ and $\mathrm{n}$ refers to mean diameter and spread parameter. To obtain the above parameters the particle size data is fit to the Rosin-Rammler exponential equation (Eq. (10)) and is shown in Fig. 4 with a size distribution of $0.5-234 \mu \mathrm{m}$. It may be noted that the value of the mean diameter is the value of $d$ at $Y_{d}=e^{-1} \approx 0.368$. The value of the spread $(n)$ which is given as input to the simulations is obtained by the following equation (Fluent, 2006).

$n=\frac{\ln \left(-\ln Y_{d}\right)}{\ln (d / \bar{d})}$

By substituting the data for $Y_{d}$ and $d / \bar{d}$ in Eq. (11) values for ' $n$ ' are obtained. The average value for ' $n$ ' (spread parameter) thus obtained is used in simulations. The spread parameter obtained in the present study is 1.009 .

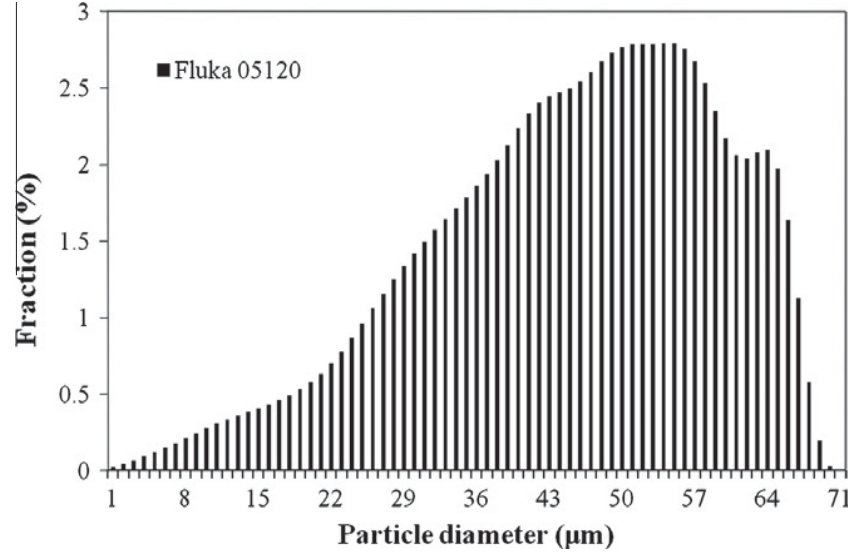

Fig. 3. Cumulative volume fraction for the carbon particle sample (Fluka, 05120).

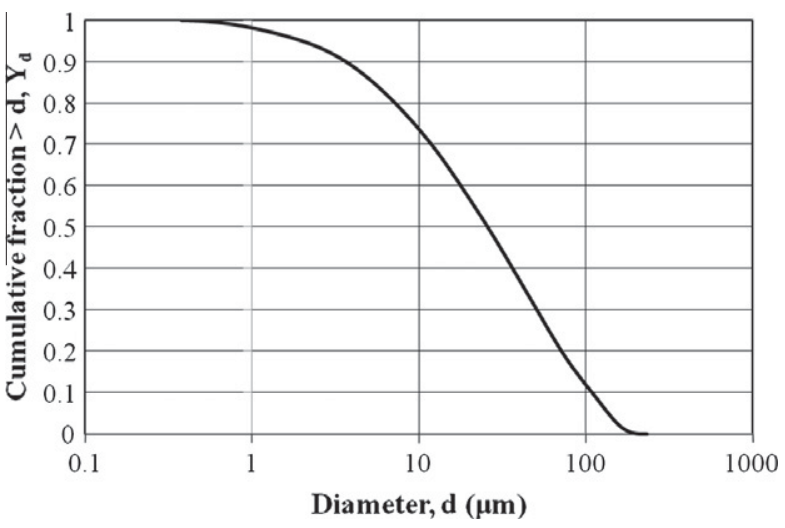

Fig. 4. Particle size data fitted to Rosin-Rammler exponential equation.

\subsection{Validation of the numerical analysis}

In order to predict the validity of the present numerical methodology, extreme conditions for particle deposition on reactor window of Kogan et al. (2004), i.e. Table 1: case \#1 and case \#8, was 


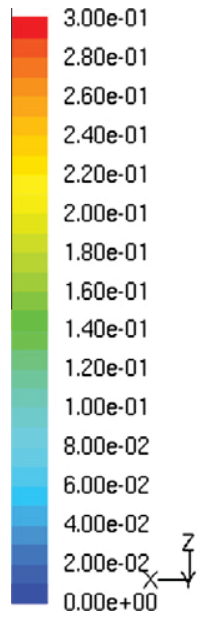

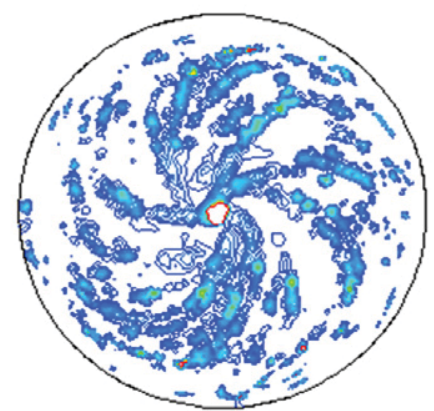

(a)

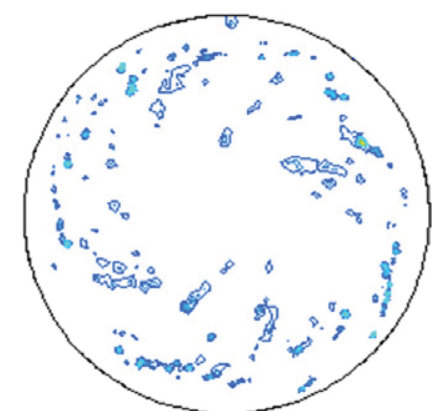

(b)

Fig. 5. Comparison of present numerical scheme with experimental results of Kogan et al. (2004) (a) when maximum particle deposition on reactor window was observed and (b) when minimum particle deposition on reactor window was observed.
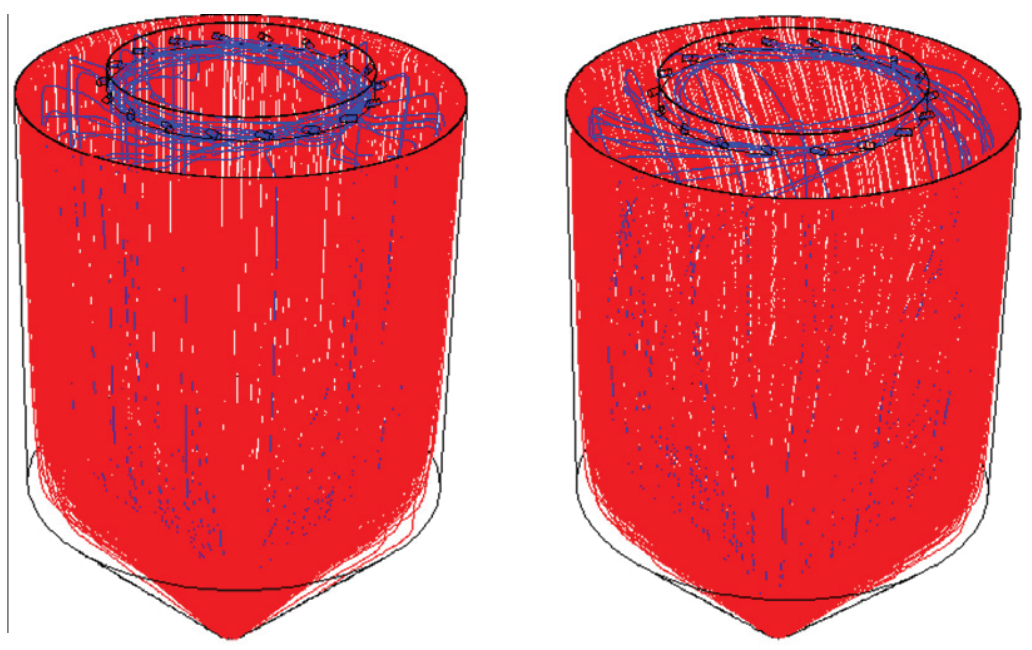

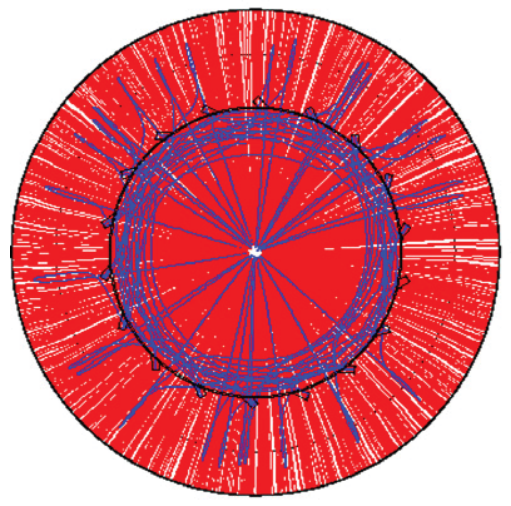

(a)

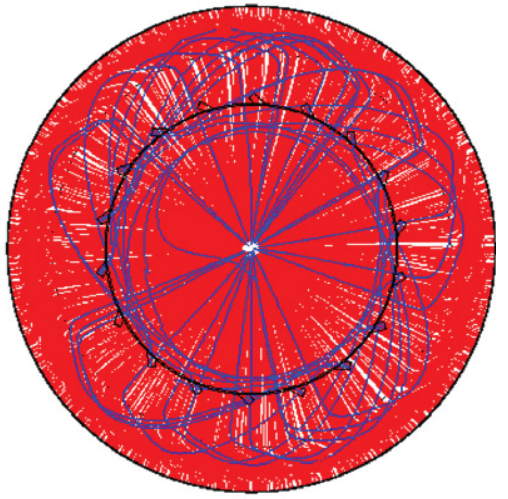

(b)

Fig. 6. Path lines for main flow: F1 (methane - blue) and wall screening: F3 (argon - red) for (a) Case: 1 (b) Case: 9. (For interpretation of the references to color in this figure legend, the reader is referred to the web version of this article.)

considered. It may be noted that Kogan et al. (2004) provides qualitative statements of particle deposition at the reactor window. Case \#1 results with substantial contamination on window whereas case \# 8 reports minimal deposition. For their reactor geometry the above considered numerical approach is adopted and the particle concentration $\left(\mathrm{kg} / \mathrm{m}^{3}\right)$ on the reactor window is plotted. Fig. 5 shows the particle concentration $\left(\mathrm{kg} / \mathrm{m}^{3}\right)$ for Cases \#1 and \#8 respectively. From Fig. 5 it may be noted that the present numerical methodology showed a good agreement to that of experimental observation of Kogan et al. (2004). 


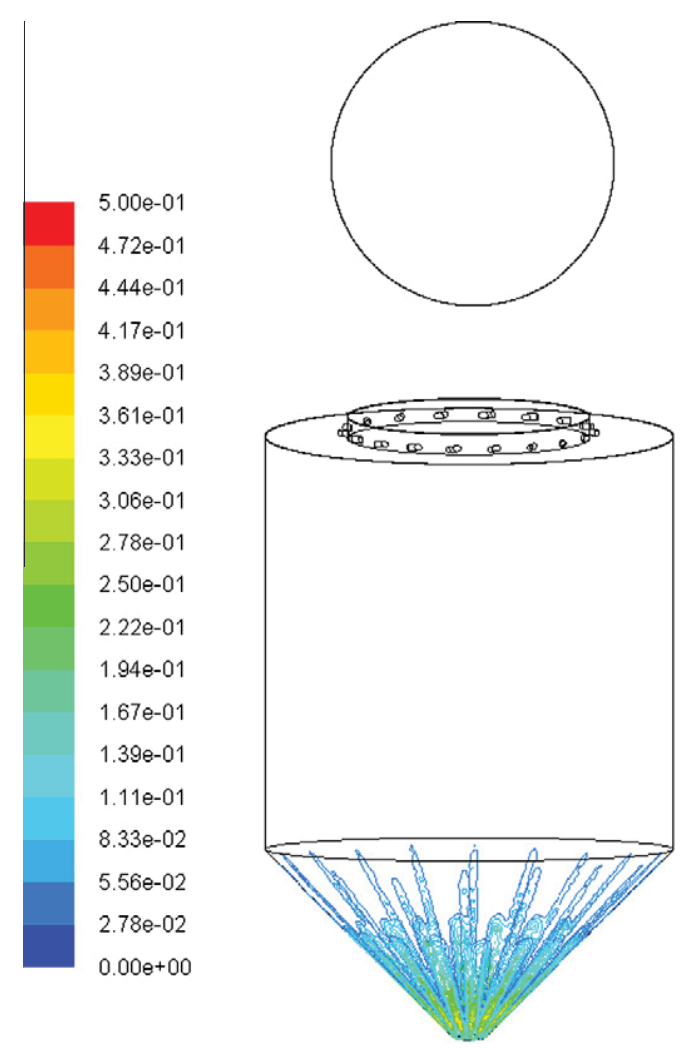

(a)
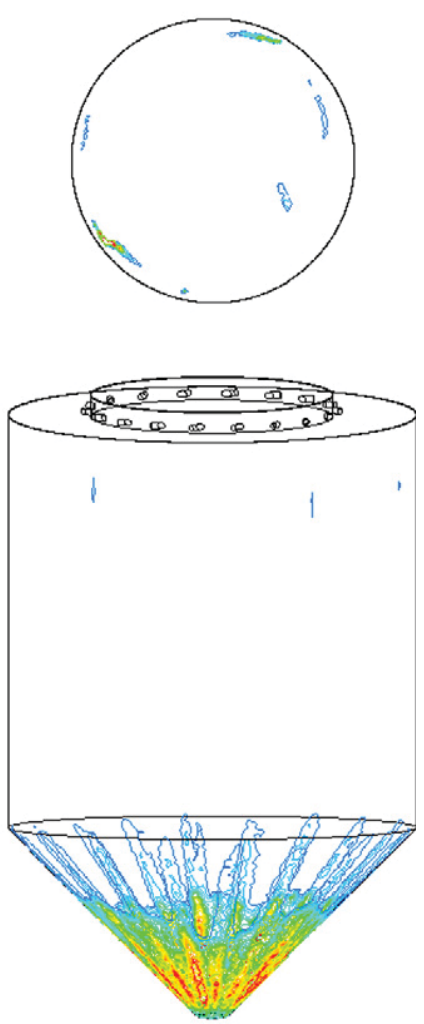

(b)

Fig. 7. Particle concentration $\left(\mathrm{kg} / \mathrm{m}^{3}\right.$ ) window (top) and wall (bottom) for: (a) Case: 1 and (b) Case: 9.

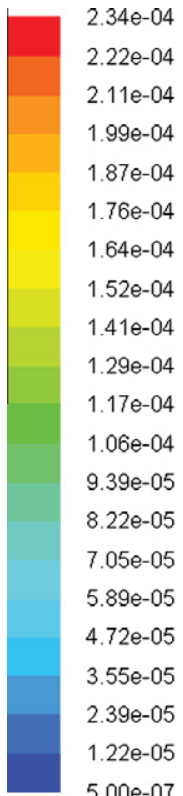

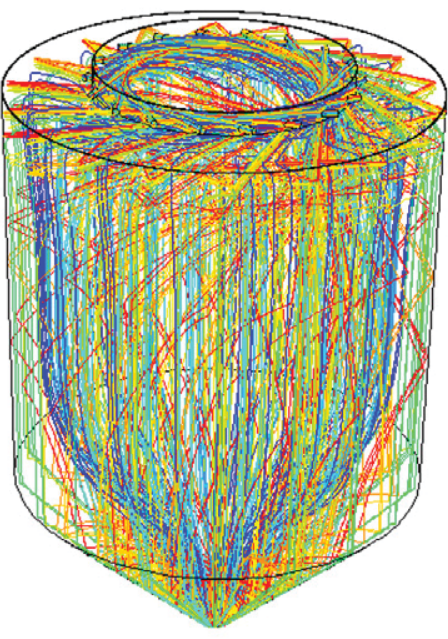

(a)

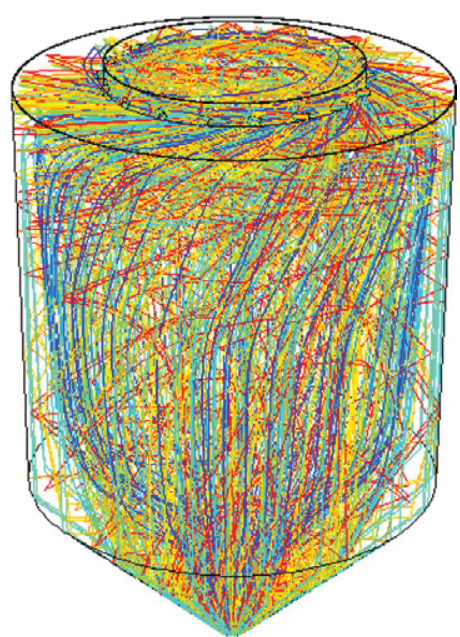

(b)

Fig. 8. Particle trajectories with lines colored by particle diameter ( $\mu \mathrm{m})$ for: (a) Case: 1 and (b) Case: 9.

The grid independence study was carried out by initially considering a course grid of 2,152,723 cells. Later the grid size has been increased to $3,346,656$ cells. To check the grid independence, velocity magnitude is plotted near the window (1-1), center (22 ) and at the exit (3-3) of the reactor as shown by dotted lines in Fig. 1. Considerable variation is observed at the window and at the exit for the velocity magnitude; hence the grid size has been increased to $4,566,775$. As the increase in grid size did not cause any significant variation in velocity magnitude, a grid size of $3,346,656$ cells has been used in this study. 


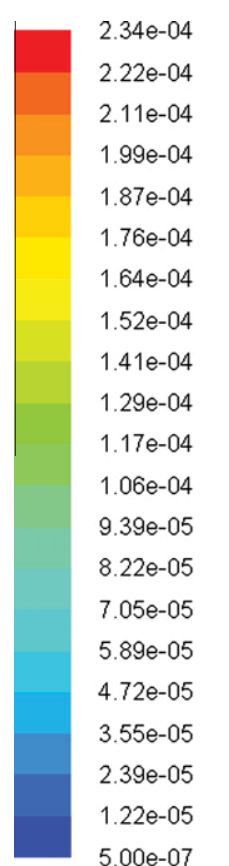

5.00 e-07

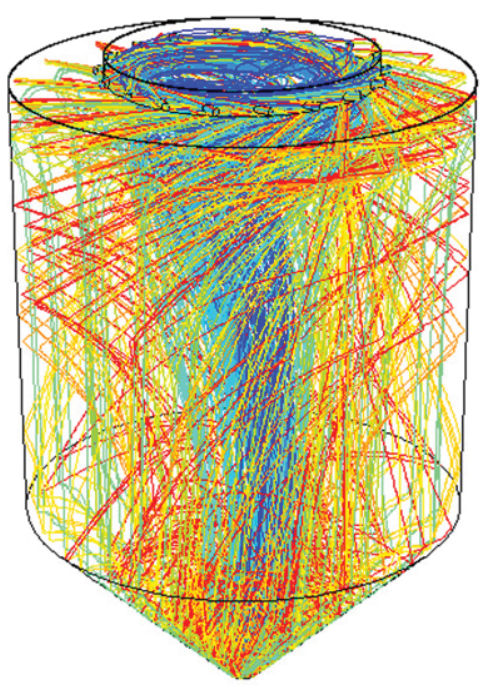

(a)

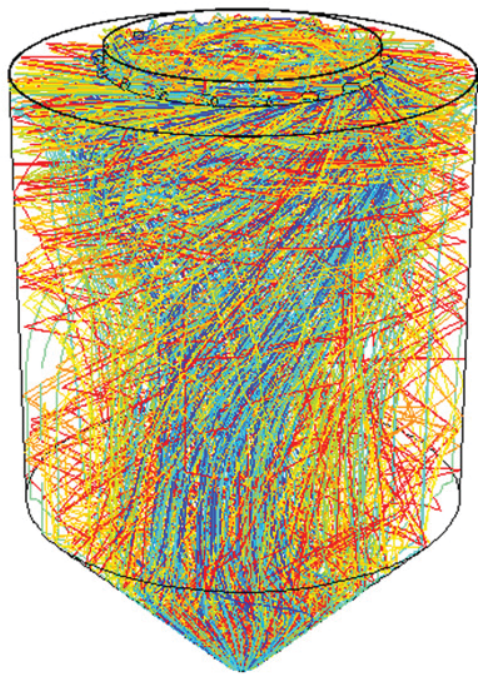

(b)

Fig. 9. Particle trajectories with lines colored by particle diameter ( $\mu \mathrm{m})$ for: (a) Case: 13 (b) Case: 15.

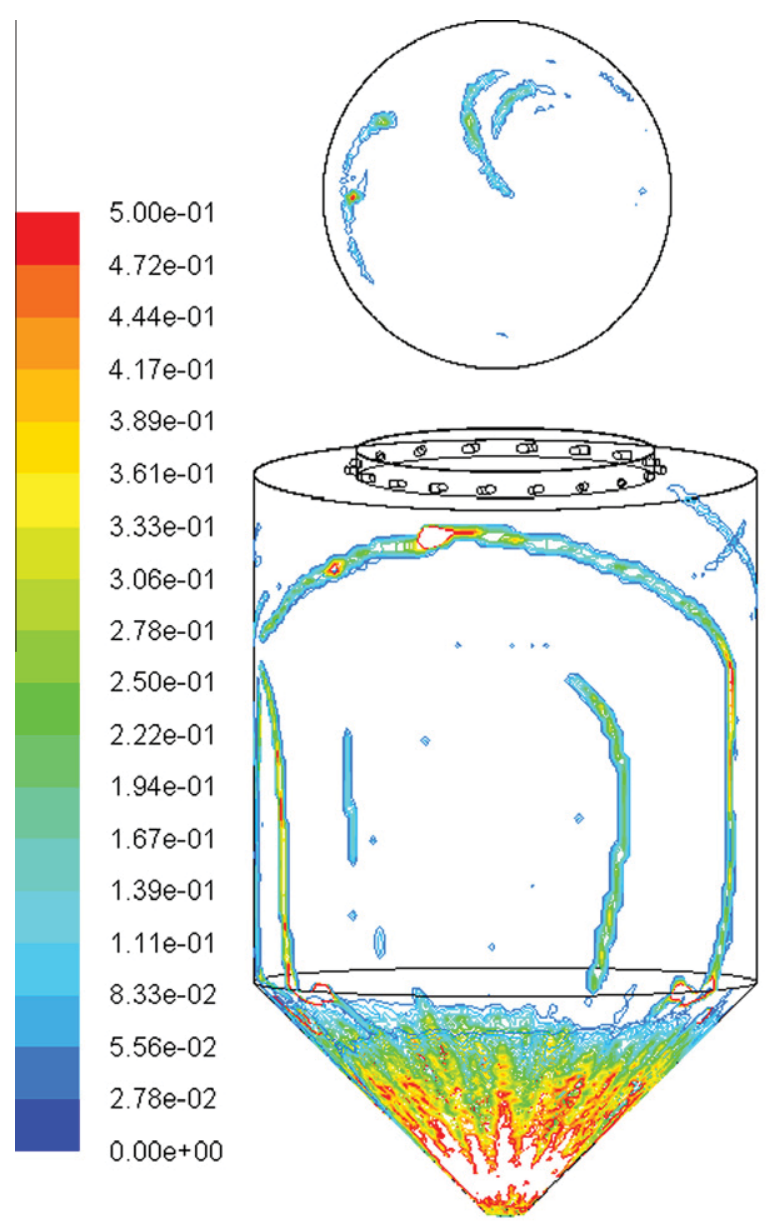

(a)
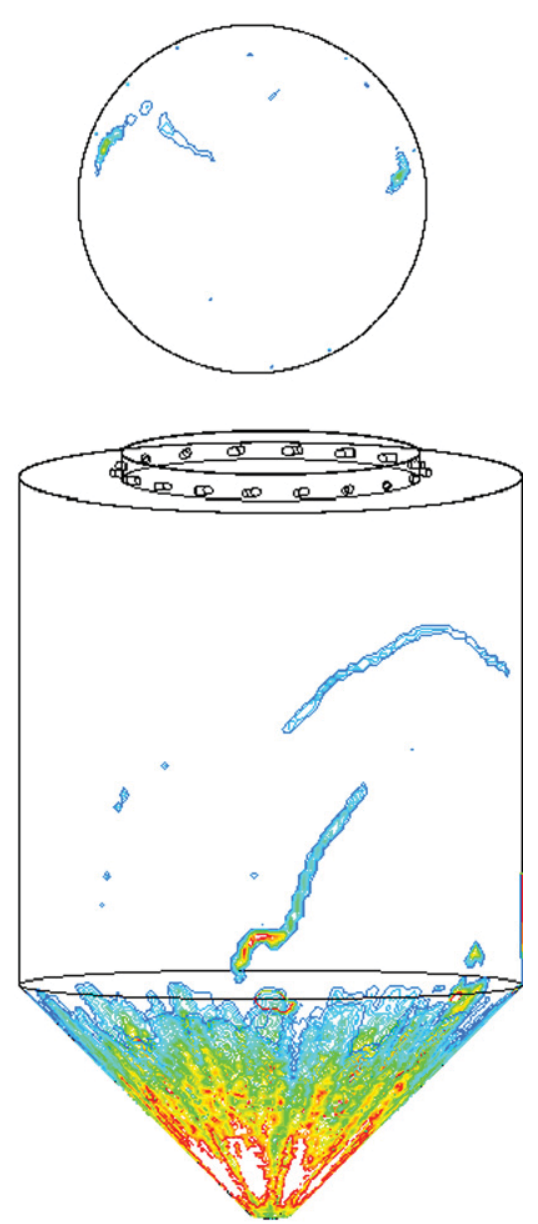

(b)

Fig. 10. Particle concentration $\left(\mathrm{kg} / \mathrm{m}^{3}\right.$ ) window (top) and wall (bottom) for: (a) Case: 17 and (b) Case: 18. 


\subsection{Mass flow rates for particles}

In the present study the mass flow rates of carbon particles have been considered by referring to the volume fractions of Maag et al. (2009). Mass flow rates of $7 \times 10^{-6}$ and $1.75 \times 10^{-5} \mathrm{~kg} / \mathrm{s}$ were used to analyze the influence of mass flow rate of the particle on particle decomposition for the aero-shielded reactor.

\section{Results and discussion}

The aim of the present study is to predict the particle deposition at the window and exit with different flow conditions for a solar reactor. Parameters such as main flow (methane) rate, type of window and wall screening gas, flow rate of carbon particles and variation of particle diameter have been considered as shown in Table 1. It is to be noted that the flow rates for the main flow have been varied from 10 to $20 \mathrm{~L} / \mathrm{min}$ by varying the mass flow rate for particles from $7 \times 10^{-6}$ to $1.75 \times 10^{-5} \mathrm{~kg} / \mathrm{s}$, and argon/hydrogen have been used for window and wall screening with the flow rates of $1 \mathrm{~L} / \mathrm{min}$ and $10 \mathrm{~L} / \mathrm{min}$. In order to study the effect of particle size the simulations have also been carried out (i) with the variation of particle diameter with a size distribution of $0.5-234 \mu \mathrm{m}$ and (ii) by taking $40 \mu \mathrm{m}$ mono sized particle diameter which is the mean value for the considered size distribution. The flow physics for particle deposition is explained by referring to the path lines for main and screening flows, and particle trajectories of carbon particles.

\subsection{Effect of main flow rate (F1)}

To study the influence of the main flow on flow behavior and particle deposition the flow rates of methane have been varied i.e. 10 and $20 \mathrm{~L} / \mathrm{min}$. In this study argon is used for both window and wall screening with the flow rates of $1 \mathrm{~L} / \mathrm{min}$ (F2) and $10 \mathrm{~L} /$ min (F3). The mass flow rate of carbon particles is taken as $7 \times 10^{-6} \mathrm{~kg} / \mathrm{s}$ with a particle size distribution of $0.5-234 \mu \mathrm{m}$ (cases: 1 and 9). Fig. 6 depicts the path lines for main flow (methane - blue) and wall screening (argon - red). A beautiful cage like argon curtain can be observed along the walls of the reactor. This kind of flow behavior is expected to behave as a shield and prevent the sticking of carbon particle to the reactor wall.

When each of the fluid elements has a flat velocity profile instead of swirl/vortex flow then the residence time will be less i.e. for a given reactor volume for the same flow conditions the formation of swirls leads to increase in residence time. In this study for a $20 \mathrm{~L} / \mathrm{min}$ of methane flow rate swirls is observed instead of a flat velocity profile. The formation of swirls instead of flat velocity profile (plug flow) is a positive sign as the residence time for methane can be increased for a given flow rate. Fig. 7 shows the particle concentration $\left(\mathrm{kg} / \mathrm{m}^{3}\right)$ at the window (top view) and walls (isometric view) of the reactor. With the increase in main flow there is an increase in particle deposition at the exit and trivial deposition at the window (Table 1 and Fig. 7b). Therefore, to analyze the behavior of particles with the increase in the main flow, the particle trajectories with lines colored by particle diameter is plotted and shown in Fig. 8. From the figure it may be observed that smaller diameter particles take the main flow and larger diameter particles move towards the outer periphery of the main flow. Based on Fig. 7 and Table 1 it may be analyzed that very few particles move towards the window and cause lower particle deposition. The increase in particle concentration at the exit with the increase in the methane flow rate from $10 \mathrm{~L} / \mathrm{min}$ to $20 \mathrm{~L} / \mathrm{min}$ may be observed in Fig. 7. Based on the particle trajectories it may be noted that as the increase in particle cloud is not allowed to proceed instantaneously through the provided outlet, the particle concentration is observed to increase at the exit.

\subsection{Effect of window screening gas (F2)}

To study the influence of window screening gas on the flow behavior and particle deposition, hydrogen (cases: 13, 14 and 15) and argon (cases: 1, 5 and 9) have been employed for window screening by varying the methane flow rate (F1) from $10 \mathrm{~L} / \mathrm{min}$ to $20 \mathrm{~L} / \mathrm{min}$. Argon is used as the wall screening with a flow rate of $10 \mathrm{~L} / \mathrm{min}$, particle flow rate of $7 \times 10^{-6} \mathrm{~kg} / \mathrm{s}$ and a particle size distribution of $0.5-234 \mu \mathrm{m}$. With hydrogen as the window screening, the shielding like flow structure near the walls shown in Fig. 6 is disturbed and the flow is attained at the middle portions of the cavity. The details of the particle concentration at the window and exit are provided in Table 1 . When argon is used as window screening (cases: 1, 5 and 9) the particle deposition at the window and exit increases with the increase of the main flow rate. But for the same flow conditions when hydrogen is used (cases: 13, 14 and 15) there is a decrease of particle deposition at the window and increase at the exit. The decrease of particle deposition at the window when hydrogen is used as window screening with the increase of the main flow from $10 \mathrm{~L} / \mathrm{min}$ to $20 \mathrm{~L} / \mathrm{min}$ is due to partially overcoming of the effect of Taylor instabilities (Kogan and Kogan, 2003). To analyze the particle deposition at the exit, particle trajectories with lines colored according to the particle diameter are shown in Fig. 9. For a main flow of $10 \mathrm{~L} / \mathrm{min}$ when hydrogen is used as window screening (case: 13), a tornado like flow structure for main flow sweeps the smaller diameter particles towards the inner core of the reactor and provides a smooth exit. The particle deposition of $0.007 \mathrm{~kg} / \mathrm{m}^{3}$ (case: 13) at the exit can be due to larger diameter particles at the conical section as observed in Fig. 9a. When the main flow is increased to $20 \mathrm{~L} / \mathrm{min}$ the mixing is more vigorous thus disturbing the wall screening. The increase

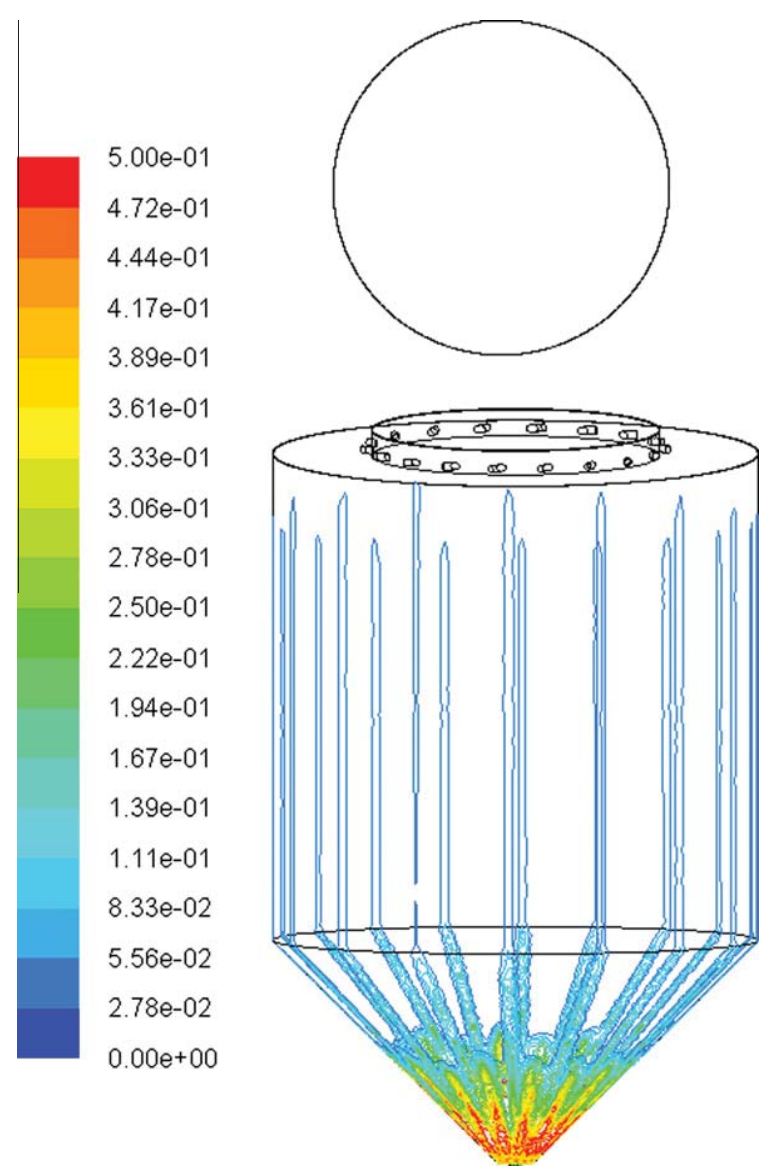

Fig. 11. Particle concentration $\left(\mathrm{kg} / \mathrm{m}^{3}\right)$ window (top) and wall (bottom) for Case: 2 . 


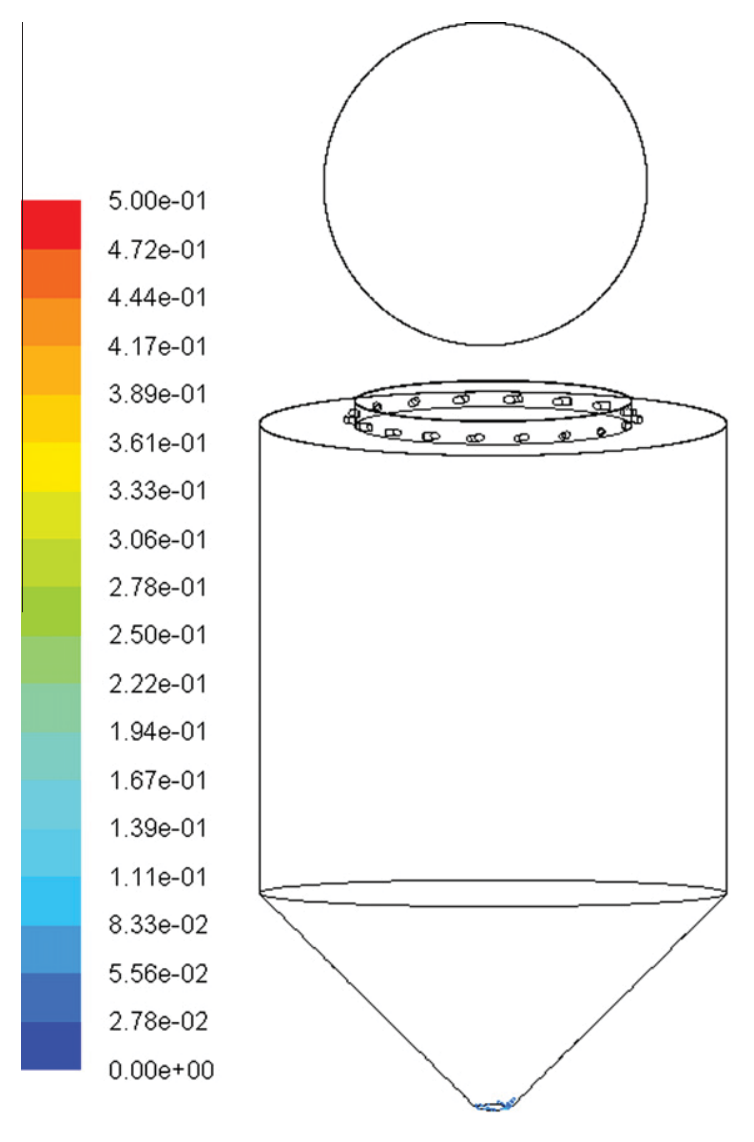

(a)

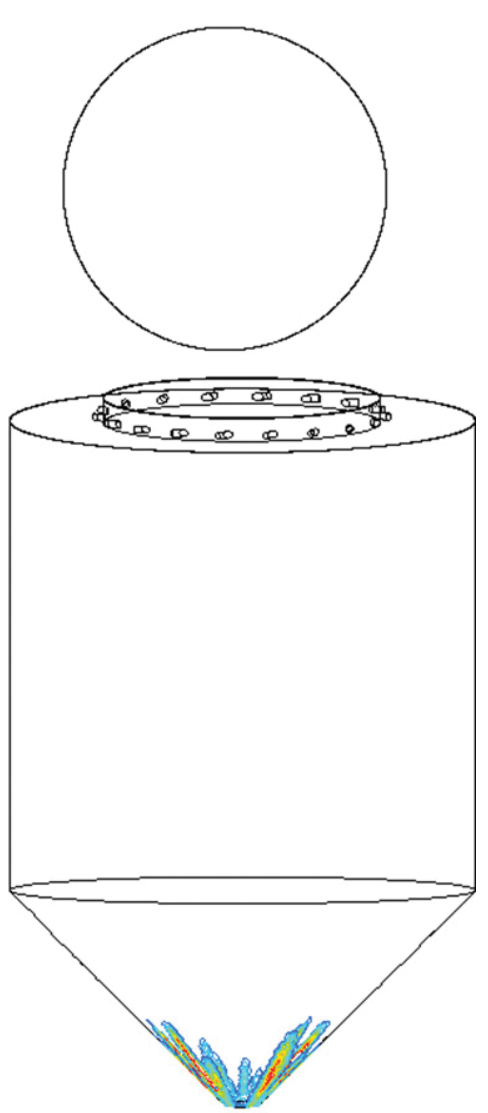

(b)

Fig. 12. Particle concentration $\left(\mathrm{kg} / \mathrm{m}^{3}\right)$ window (top) and wall (bottom) for (a) Case: 3 (b) Case: 11 .

of a particle cloud as shown in Fig. 9b does not provide smooth exit leading to more particle deposition at the exit.

\subsection{Effect of wall screening gas (F3)}

To analyze the influence of wall screening gas on the flow behavior and particle deposition, hydrogen has been considered as a window and a wall screening gas with flow rates of $1 \mathrm{~L} / \mathrm{min}$ and $10 \mathrm{~L} / \mathrm{min}$ (cases : 16, 17 and 18). In this study the methane flow rate has been varied from $10 \mathrm{~L} / \mathrm{min}$ to $20 \mathrm{~L} / \mathrm{min}$ with a particle mass flow rate of $7 \times 10^{-6} \mathrm{~kg} / \mathrm{s}$ having the variation of particle diameter from 0.5 to $234 \mu \mathrm{m}$. The particle concentration at the window and walls of cases: 17 and 18 is shown in Fig. 10. When hydrogen is used as wall screening (cases: 17 and 18) instead of argon (cases: 14 and 15) the particle concentration at the exit is observed to be considerably higher and nearly same at the window. This is due to the fact that as hydrogen is less dense, the main flow is observed to shear off the wall screening and lead to particle deposition at the walls of the reactor. Also, when hydrogen is used as wall screening the main flow is dispensed throughout the reactor cavity, as the smaller diameter particles take the path of the main flow as observed in the previous simulations. The conical section becomes crowded due to the flow behavior and does not provide a smooth exit leading to an increase in particle deposition at the exit.

\subsection{Effect of particle mass flow rate}

To analyze the influence of increase in the particle mass flow rate, the flow rate of the particles has been increased from $7 \times 10^{-6} \mathrm{~kg} / \mathrm{s}$ to $1.75 \times 10^{-5} \mathrm{~kg} / \mathrm{s}$. In this study the main flow has been considered to be $10 \mathrm{~L} / \mathrm{min}$ and argon is used both for window and wall screening with the flow rates of $1 \mathrm{~L} / \mathrm{min}$ and $10 \mathrm{~L} / \mathrm{min}$ with a particle size distribution of $0.5-234 \mu \mathrm{m}$ (cases: 1 and 2). The reason for selecting argon as both window and wall screening is due to the fact that it showed comparatively less particle deposition to that of hydrogen for the flow rates of $10 \mathrm{~L} / \mathrm{min}$ and $15 \mathrm{~L} /$ min. Fig. 11 shows the particle concentration at the reactor window, walls and exit for case: 2 . From cases: 1 and 2 provided in Table 1 it may be observed that the particle deposition at the exit has increased from $0.058 \mathrm{~kg} / \mathrm{m}^{3}$ to $0.132 \mathrm{~kg} / \mathrm{m}^{3}$. A comparison of Figs. $7 \mathrm{a}$ and 11 show that with the increase in the particle mass flow rate the wall screening is not able to restrict the carbon particles and led to the deposition of particle deposition at the vertical walls.

\subsection{Effect of particle diameter}

Based on the simulations it may be noted that with the increase of the particle cloud at the conical section more particle deposition is observed at the exit. The larger diameter particles move towards the wall due to inertia and collide with the wall. To study the influence of particle diameter, a $40 \mu \mathrm{m}$ mono sized particle diameter which is the mean value for the particle distribution of 0.5$234 \mu \mathrm{m}$ was utilized and simulations carried out with the variation of the main flow from $10 \mathrm{~L} / \mathrm{min}$ to $20 \mathrm{~L} / \mathrm{min}$ (cases: 3, 4, 7, 8, 11 and 12). Argon is used as both the window and wall screening gas with the flow rates of $1 \mathrm{~L} / \mathrm{min}$ and $10 \mathrm{~L} / \mathrm{min}$. Fig. 12 shows the particle concentration with the variation of the main flow rate and with a mass flow rate of $7 \times 10^{-6} \mathrm{~kg} / \mathrm{s}$ (cases: 3 and 11). For a flow condition of $10 \mathrm{~L} / \mathrm{min}$ the deposition at the exit can be observed to be almost nil and with $20 \mathrm{~L} / \mathrm{min}$, the particle accumulation is observed 


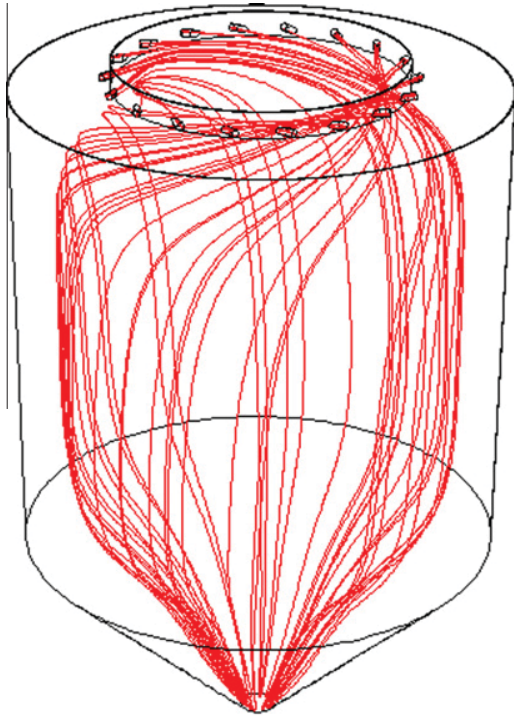

(a)

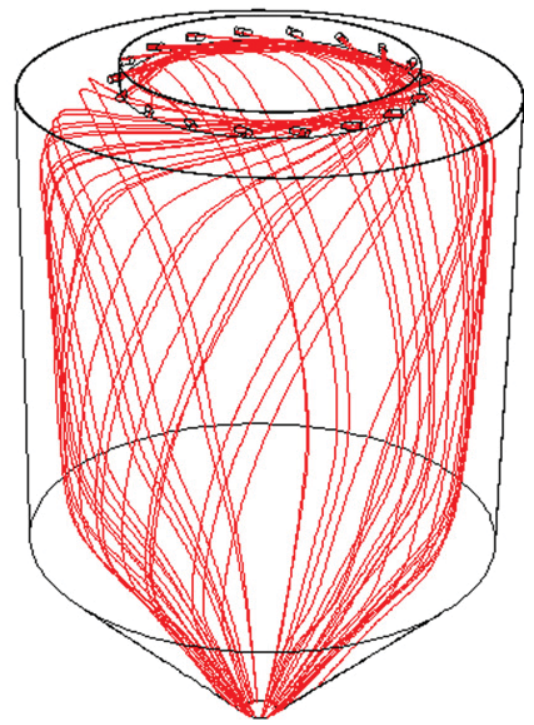

(b)

Fig. 13. Particle trajectories colored by particle diameter $(40 \mu \mathrm{m})$ for: (a) Case: 3 and (b) Case: 11.

to increase at the exit. To analyze this phenomenon the particle trajectories have been plotted for the same condition with the increase in flow rate and are shown in Fig. 13. A comparing Fig. 13a and $b$ shows that with the increase of flow rate from $10 \mathrm{~L} / \mathrm{min}$ to $20 \mathrm{~L} / \mathrm{min}$ the thickness of the particle cloud increases, i.e. the particles tend to move towards the wall. Due to this the particle deposition at the exit portion increases with the increase in flow rate.

\section{Conclusions}

In the present study CFD analysis has been carried out to predict the particle deposition at the reactor's window, walls and exit for aero-shielded solar cyclone reactor. The numerical validation for particle deposition is done by comparing with the experimental results of Kogan et al. (2004). A thorough numerical investigation has been carried out to study the influence of methane flow rate, type of window and wall screening gas, mass flow rate of particles and variation of particle diameter with a size distribution of $0.5-$ $234 \mu \mathrm{m}$. The details of particle injection in simulations have been taken for activated charcoal (Fluka, 05120) which is experimentally obtained by laser diffraction particle size analyzer. Results are presented in terms of path lines, particle concentration and particle trajectories. It is observed that by appropriate selection of parameters the concept of an aero-shielded solar cyclone can be an attractive option to overcome the problem of carbon particle deposition at the window and exit. Based on the parametric study the findings can be summarized as follows:

(i) When argon is used as window and wall screening gas a curtain like shield is observed adjacent to the walls of the reactor. This shield like flow structure assisted in protecting the reactor walls from carbon deposition.

(ii) For a wall screening flow rate of $10 \mathrm{~L} / \mathrm{min}$ the increase in particle flow rate from $7 \times 10^{-6} \mathrm{~kg} / \mathrm{s}$ to $1.75 \times 10^{-5} \mathrm{~kg} / \mathrm{s}$ lead to the increase in particle deposition.

(iii) When hydrogen is used as window screening the increase in the main flow rate led to the decrease in particle deposition at the window.

(iv) Hydrogen can be ruled out as a wall screening due to high particle deposition at the exit. (v) With the increase of flow rate the particle cloud at the conical section is observed to increase which in turn led to the particle deposition at the exit (refer Figs. 8, 9 and 13).

(vi) From Table 1 it is observed that with the increase of the main flow rate (i.e. from $10 \mathrm{~L} / \mathrm{min}$ to $20 \mathrm{~L} / \mathrm{min}$ ) the particle deposition at the exit increases. Based on particle trajectories it is noted that the crowding of the particles at the conical section lead to the increase of particle deposition at the exit. Therefore it is expected that by fine-tuning of the exit/ conical section of the aero-shielded reactor the problem of carbon deposition at the exit can be solved for wider flow rates and particle size distribution.

(vii) Based on the considered parametric study (Table 1) the aeroshielded concept is observed to be very effective with $40 \mu \mathrm{m}$ mono-sized particles with a methane flow rate of $10 \mathrm{~L} / \mathrm{min}$.

\section{Acknowledgement}

This publication was made possible by NPRP grant \# [09-671-2255] from the Qatar National Research Fund (a member of Qatar Foundation).

\section{References}

Abanades, S., Flamant, G., 2005. Production of hydrogen by thermal methane splitting in a nozzle-type laboratory-scale solar reactor. Int. J. Hydrogen Energy 30, 843-853.

Abanades, S., Flamant, G., 2006. Solar hydrogen production from the thermal splitting of methane in a high temperature solar chemical reactor. Sol. Energy 80, 1321-1332.

Abanades, S., Flamant, G., 2007. Experimental study and modeling of a hightemperature solar chemical reactor for hydrogen production from methane cracking. Int. J. Hydrogen Energy 32, 1508-1515.

Abanades, S., Flamant, G., 2008. High-temperature solar chemical reactors for hydrogen production from natural gas cracking. ChemEngComm 195, 11591175.

Dahl, J.K., Buechler, K.J., Weimer, A.W., Lewandowski, A., Bingham, C., 2004. Solarthermal dissociation of methane in a fluid-wall aerosolflow reactor. Int. J. Hydrogen Energy 29, 725-736.

Dahl, J.K., Weimer, A.W., Graggen, A.Z., Steinfeld, A., 2005. Two dimensional axisymmetric model of a solar-thermal fluid wall aerosol flow reactor. ASME J. Sol. Energy Eng. 127, 76-85. 
Flamant, G., Rodat, S., Abanades, S., 2011. of hydrogen and carbon black from solar thermal methane splitting in a tubular reactor prototype. Sol. Energy 85, 645652 .

Fluent. Fluent version 6.3 users' manual. Fluent Inc., 2006.

Habibi, A., Merci, B., Heynderickx, G.J., 2007. Impact of radiation models in CFD simulation of steam cracking furnaces. Comput. Chem. Eng. 31, 1389-1406

Hirsch, D., Steinfeld, A., 2004. Solar hydrogen production by thermal decomposition of natural gas using a vortex-flow reactor. Int. J. Hydrogen Energy 29, 47-55.

Hirsch, D., Epstein, M., Steinfeld, A., 2001. The solar thermal decarbonization of natural gas. Int. J. Hydrogen Energy 26, 1023-1033.

Klein, H.H., Karni, J., Ben-Zvi, R., Bertocchi, R., 2007. Heat transfer in a directly irradiated solar receiver/reactor for solid-gas reactions. Sol. Energy 81, 12271239.

Kogan, A., Kogan, M., 2002. The tornado flow configuration - an effective method for screening of a solar reactor window. ASME J. Sol. Energy Eng. 124, 206-214.

Kogan, M., Kogan, A., 2003. Production of hydrogen and carbon by solar thermal methane splitting. I. The unseeded reactor. Int. J. Hydrogen Energy 28, 11871198.

Kogan, A., Kogan, M., Barak, S., 2004. Production of hydrogen and carbon by solar thermal methane splitting. II. Room temperature simulation tests of seeded solar reactor. Int. J. Hydrogen Energy 29, 1227-1236.

Kogan, A., Israeli, M., Alcobi, E., 2007. Production of hydrogen and carbon by solar thermal methane splitting. IV. Preliminary simulation of a confined tornado flow configuration by computational fluid dynamics. Int. J. Hydrogen Energy 32, 4800-4810.

Maag, G., Zanganeh, G., Steinfeld, A., 2009. Solar thermal cracking of methane in a particle-flow reactor for the co-production of hydrogen and carbon. Int. J. Hydrogen Energy 34, 7676-7685.

Meier, A., Ganz, J., Steinfeld, A., 1996. Modeling of a novel high-temperature solar chemical reactor. ChemEngSci 51, 3181-3186.

Ozalp, N., JayaKrishna, D., 2010. CFD analysis on the influence of helical carving in a vortex flow solar reactor. Int. J. Hydrogen Energy 35, 6248-6260.

Ozalp, N., Kanjirakat, A., 2010a. Lagrangian characterization of multi-phase turbulent flow in a solar reactor for particle deposition prediction. Int. J. Hydrogen Energy 35, 4496-4507.
Ozalp, N., Kanjirakat, A., 2010b. A CFD study on the effect of carbon particle seeding for the improvement of solar reactor performance. ASME J. Heat Transfer 132 (12), 122901-122907.

Patrianakos, G., Kostoglou, M., Konstandopoulos, A., 2011. One-dimensional model of solar thermal reactors for the co-production of hydrogen and carbon black from methane decomposition. Int. J. Hydrogen Energy 36, 189-202.

Patrianakos, G., Kostoglou, M., Konstandopoulos, A., 2012. Effect of seeding on hydrogen and carbon particle production in a $10 \mathrm{MW}$ solar thermal reactor for methane decomposition. Int. J. Hydrogen Energy 37 (21), 16570-16580, <http:// www.sciencedirect.com/science/article/pii/S0360319912003680>.

Rodat, S., Abanades, S., Sans, J.L., Flamant, G., 2009a. Hydrogen production from solar thermal dissociation of natural gas: development of a $10 \mathrm{~kW}$ solar chemical reactor prototype. Sol. Energy 83, 1599-1610.

Rodat, S., Abanades, S., Flamant, G., 2009b. High-temperature solar methane dissociation in a multitubular cavity-type reactor in the temperature range 1823-2073 K. Energy Fuels 23, 2666-2674.

Rodat, S., Abanades, S., Sans, J.L., Flamant, G., 2010. A pilot-scale solar reactor for the production of hydrogen and carbon black from methane splitting. Int. J. Hydrogen Energy 35, 7748-7758.

Steinfeld, A., Brack, M., Meier, A., Weidenkaff, A., Wuillemin, D., 1998. A solar chemical reactor for co-production of zinc and synthesis gas. Energy 23, 803814.

Trommer, D., Hirsch, D., Steinfeld, A., 2004. Kinetic investigation of the thermal decomposition of $\mathrm{CH}_{4}$ by direct irradiation of a vortex-flow laden with carbon particles. Int. J. Hydrogen Energy 29, 627-633.

Valdes-Parada, F.J., Romero-Paredes, H., Espinosa-Paredes, G., 2011. Onedimensional model of solar thermal reactors for the co-production of hydrogen and carbon black from methane decomposition. Int. J. Hydrogen Energy 36, 3354-3363.

Vidyasagar, S., Jaya Krishna, D., Ozalp, N., 2011. Residence time distribution and flow field study of aero-shielded solar cyclone reactor for emission-free generation of hydrogen. Int. J. Hydrogen Energy 36 (21), 13488-13500.

Wyss, J., Martinek, J., Kerins, M., Dahl, J.K., Weimer, A., Lewandowski, A., Bingham, C., 2007. Rapid solar-thermal decarbonization of methane in a fluid-wall aerosol flow reactor - fundamentals and application. Int. J. Chem. Reactor Eng. 5, 1-28. 